\title{
Commentaries
}

\section{Oesophageal pain in coronary artery disease}

Up to $26 \%$ of patients with angina-like chest pain sufficiently severe to necessitate more invasive examinations have normal coronary arteries on arteriography. ${ }^{1}$ Since the late 1970 s, the oesophagus has gained notoriety as a possible cause of the chest pain in these patients. Depending upon the criteria used to accept an oesophageal origin of the pain, up to $50 \%$ of patients with normal coronary arteries have oesophageal pain. Gastroenterologists now widely accept that the best and possibly the only way to determine whether the oesophagus is the likely cause of the chest pain is to show a temporal correlation between the pain attack and an abnormal oesophageal event, such as acid reflux or severe motor disturbances.

Since the development of 24 hour $\mathrm{pH}$ and pressure measurements by the Leuven group, prolonged recordings have become a standard investigation in patients with noncardiac chest pain. ${ }^{2}$ These measurements, which attempt to correlate symptoms with abnormal oesophageal events, led to the finding that most of the spontaneous pain attacks were reflux related, although many of these patients have a normal acid exposure on quantitative analysis of 24 hour $\mathrm{pH}$ monitoring. This has been called the acid hypersensitive oesophagus. ${ }^{3}$

Analogous to the use of exercise tests in cardiology to provoke myocardial ischaemia, several provocation tests have been used in an attempt to identify the oesophagus as the origin of chest pain. Provocation by acid or by motility stimulating agents, mechanical stimulation by balloon distension and other stimuli have all been used. The acid perfusion and edrophonium tests seem to be the most reliable and are able to detect most patients with non-cardiac chest pain of oesophageal origin. ${ }^{4}$

If patients have chest pain which seems to be exclusively related to acid (positive acid perfusion test or spontaneous pain related to acid reflux, or both), they are considered to have an acid sensitive oesophagus. Similarly, patients with a positive edrophonium test and/or a positive distension test and/or spontaneous pain in relation to severe dysmotility have a mechano-sensitive oesophagus. Patients who are sensitive to several stimuli are considered to have an irritable oesophagus. Acid plays a major role in these patients as those with an acid sensitive oesophagus and an irritable oesophagus are far more common than patients with a mechano-sensitive oesophagus. ${ }^{4}$

Schofield et al were the first to describe oesophageal abnormalities in patients with proven coronary artery disease. During standard oesophageal manometry, abnormalities were found in $2 / 20(10 \%)$ patients with coronary artery disease and in 23/52 (44\%) patients with normal coronary angiograms. ${ }^{5}$ In 1990 Bortolotti et al described oesophageal abnormalities, especially reflux, in 14/18 patients with coronary artery disease, in whom treatment with nitroderivatives and calcium antagonists had become partially ineffective. ${ }^{6}$ Lux et al compared pain related oesophageal motility, gastro-oesophageal reflux and ST segment deviation in patients with intermittent chest pain and normal (30 patients) or pathological coronary angio- graphy (15 patients). Pain correlated abnormal motility or gastro-oesophageal reflux occurred at the same frequency in patients with normal and pathological coronary angiography. Moreover, simultaneous ECG recording revealed significant correlation of ST segment deviation and gastrooesophageal reflux or abnormal motility in patients with coronary artery stenoses. ${ }^{7}$

The study by Cooke et al in this issue (see page 323 ) is the first to compare prospectively the incidence of oesophageal abnormalities in relation to chest pain in patients with normal coronary angiograms (61 patients) and in a small group of so-called controls with proven angina pectoris (25 patients). The authors concluded that oesophageal function tests (standard manometric study, acid perfusion test, 24 hour $\mathrm{pH}$ monitoring) were capable of implicating the oesophagus as a source of pain in patients with normal angiograms $(44 \%)$ and in patients with coronary artery disease $(36 \%)$. With the exception of simultaneous contractions during standard manometry $(6.7 v 0.8 \%)$, however, the incidence of abnormal testing (acid perfusion test, acid exposure) and in particular the correlation of gastrooesophageal reflux with chest pain were as common in patients with normal coronary angiograms as in controls with angina (23 $v 24 \%)$. Neither the chest pain characteristics (duration, predictability, rest pain, typical pain) nor the presence of additional oesophageal symptoms (heartburn, dysphagia, waterbrash) were predictive of an oesophageal abnormality. However, pain characteristics (duration, predictability, rest pain) and additional symptoms (dysphagia, variable stool habits) differed significantly between patients with normal coronary arteries and patients with coronary artery disease. Apparently, chest pain of oesophageal origin does exist in patients with coronary artery disease and is as frequent as in patients with normal coronary arteries. Reflux is the key factor in both patient groups.

Some studies have suggested that reflex coronary ischaemia is the mechanism underlying acid induced pain. Acid perfusion tests in patients with coronary artery disease may induce myocardial ischaemia ${ }^{8}$ and a lower exertional angina threshold. ${ }^{9}$ It has also been shown recently that acid stimulation of the oesophagus may lead to reduced coronary blood flow. ${ }^{10}$ Simultaneous $\mathrm{pH}$ monitoring and ECG recordings have also shown a significant correlation between ST segment deviation and gastro-oesophageal reflux in patients with coronary artery disease. ${ }^{7}$

In conclusion, gastro-oesophageal reflux is probably responsible for a number of episodes of chest pain in patients with coronary artery disease, and this is as frequent as in patients with chest pain and normal coronary arteries. The exact mechanism by which chest pain is induced after stimulation of the oesophageal mucosa by acid remains speculative. Intermittent chest pain of cardiac and oesophageal origin cannot be differentiated on the basis of the case history or the clinical picture, or both. Further studies are needed to clarify the benefit (if any) of acid secretion blocking agents as sole or concomitant treatment in these patients.

Internal Medicine,

G GHILLEBERT

Heilig Hartziekenhuis,

Wilgenstraat 2,

8800 Roeselare, Belgium

Department of Gastroenterology,

J JANSSENS

University Hospital Gasthuisberg,

K.U. Leuven, 3000 Leuven, Belgium 
1 Nevens F, Janssens J, Piessens J, et al. Prospective study on prevalence of oesophageal chest pain in patients referred on an elective basis to a cardiac

2 Janssens J, Vantrappen G, Ghillebert G. 24-hour recording of oesophageal pressure and $\mathrm{pH}$ in patients with noncardiac chest pain. Gastroenterology 1986;90:1978-84

3 Shi G, Bruley des Varannes S, Scarpignato C, et al. Reflux-related symptoms in patients with normal oesophageal exposure to acid. The acid hypersensitive oesophagus. Gut 1995;37:457-64.

4 Ghillebert G, Janssens J. Provocation tests versus 24-h pH and pressure measurements. Eur 7 Gastroenterol Hepatol 1995;7:1141-6.

5 Schofield PM, Whorwell PJ, Brooks NH, et al. Oesophageal function in patients with angina pectoris: a comparison of patients with normal coronary angiograms and patients with coronary artery disease. Digestion $1989 ; 42: 70-8$
6 Bortolloti M, Marzocchi A, Bacchelli S, et al. The oesophagus as a possible cause of chest pain in patients with and without angina pectoris. Hepatogastroenterology 1990;37:316-18.

7 Lux G, Van Els J, The GS, et al. Ambulatory oesophageal pressure, $\mathrm{pH}$ and ECG recording in patients with normal and pathological coronary angiography and intermittent chest pain. Neurogastroenterol Motil 1995;7: $23-30$.

8 Mellow MH, Simpson AG, Watt L, et al. Oesophageal acid perfusion in coronary artery disease: Induction of myocardial ischemia. Gastroenterology 1983;85:306-12.

9 Davies AH, Page Z, Rush EM, et al. Oesophageal stimulation lowers exertional angina threshold. Lancet 1985;i:1011-14.

10 Chaukan A, Patch MC, Schoffield PM. Effect of oesophageal acid instillation on coronary blood flow. Lancet 1993;341:1309-10.

\section{Nitric oxide as an antimicrobial agent: does $\mathrm{NO}$ always mean NO?}

Nitric oxide (NO) synthesised from L-arginine subserves multiple physiological functions in the cardiovascular, respiratory, gastrointestinal, genitourinary, and central and peripheral nervous systems. ${ }^{1}$ But synthesis of NO also contributes to host defence and seems to have cytostatic and cytotoxic effects against certain pathogens, and even against host cells themselves. ${ }^{1}$ How is this double act achieved? What determines the switch from physiological mediator to lethal gas and how is bacterial killing achieved?

The simple and standard answer to the dual action of $\mathrm{NO}$ is that its effects depend on the amounts generated and the local concentrations achieved. In the nanomolar concentrations generated by constitutive $\mathrm{NO}$ synthase (NOS) isoforms, NO acts as a cell signalling molecule and interacts preferentially with its physiological target enzymes - the most significant of which seem to be soluble guanylyl cyclase and possibly cytochrome $\mathrm{C}$ oxidase. At the higher concentrations generated when the other enzymes become targets for NO action the cytokine induced isoform of NOS (iNOS) is expressed in cells. Haem containing enzymes, enzymes with $\mathrm{Fe}-\mathrm{S}$ clusters including aconitase, NADH dehydrogenase and succinate dehydrogenase, the non-haem metalloenzymes, ribonucleotide reductase and DNA itself are all susceptible to inhibition or damage when NO output is high. Consistent with this high versus low output explanation, soluble guanylyl cyclase and cytochrome $\mathrm{C}$ oxidase are reversibly affected by NO (stimulation and inhibition respectively) with near maximal effects occurring in the nanomolar range of $\mathrm{NO}$ concentrations whereas effects on other enzymes occur only in the micromolar range and are often irreversible.

Despite the simplicity and attractiveness of the low versus high output theory, it is almost certainly only partially correct. Many reports indicate that organisms which seem to be killed following induction of the L-arginine/NO pathway in immune cells are resistant to the effects of NO itself (at least under aerobic conditions). For example, although the growth of Staphylococcus aureus is potently inhibited by NO, Salmonella typhimurium, Escherichia coli and Listeria monocytogenes seem to be resistant. ${ }^{2}$ Perhaps it should come as no surprise that certain bacteria are resistant to the actions of NO. NOS has been detected in bacteria ${ }^{3}$ and presumably the NO serves some useful physiological function within the microbe. Furthermore, many bacteria are able to denitrify nitrate to nitrite and then to gaseous products including NO. ${ }^{4}$ Pseudomonas aeruginosa is a good example of a clinically important denitrifying bacterium. Such bacteria possess a NO reductase pathway which con- verts $\mathrm{NO}$ to nitrous oxide $\left(\mathrm{N}_{2} \mathrm{O}\right)$ and ultimately to nitrogen. Mutation of NO reductase is lethal for certain bacteria, ${ }^{4}$ suggesting that even for NO producers it is important to ensure that the intracellular concentration of NO does not rise too far. Certain bacteria that are not considered as denitrifying also seem to have the ability to reduce nitrate to NO. The enteric bacteria $E$ coli, Klebsiella pneumonia, S typhimurium, Shigella sonnei, and Proteus mirabilis all possess nitrate reductase and when grown under anaerobic conditions can metabolise nitrate to NO via nitrite. ${ }^{5}$ Given that nitrate concentrations in many biological fluids are in the order of $50 \mu \mathrm{M}$, significant amounts of NO might be generated through the NOS independent pathway.

If NO itself is often not the toxic species, or if bacteria are able to metabolise and deactivate $\mathrm{NO}$, how does activation of the L-arginine/NO pathway cause bacterial stasis and death? One possibility is that $\mathrm{NO}$ becomes cytotoxic only when generated together with superoxide $\left(\mathrm{O}_{2}^{-}\right)$. NO and $\mathrm{O}_{2}^{-}$interact to form peroxynitrite $\left(\mathrm{ONOO}^{-}\right)$a powerful oxidant species that is toxic to many prokaryotic and eukaryotic cells. Inducible NOS and the phagocyte NADPH oxidase that generates $\mathrm{O}_{2}^{-}$are differentially regulated but both systems are induced by inflammatory stimuli and so co-production of $\mathrm{NO}$ and $\mathrm{O}_{2}^{-}$is common in activated phagocytes. Alternatively, peroxynitrous acid $(\mathrm{ONOOH})$ may form as the result of interaction between nitrite and hydrogen peroxide under mildly acidic conditions, and this can kill $E$ coli. ${ }^{6}$

A third possible route for NO mediated cytotoxicity relies upon the formation of S-nitrosothiols (RSNO). ${ }^{7}$ Paradoxically, many RSNOs seem to have profound bacteriostatic effects on bacteria including those such as $E$ coli and $S$ typhimurium that are resistant to authentic NO. RSNOs react with sulphydryl groups on proteins and this can alter protein function to lead to cell stasis or death. The potential importance of RSNOs as bacteriostatic agents is exemplified by the finding that salmonella mutants that are deficient in active peptide transport and cannot transport glutathione are resistant to the toxic effects of the RSNO S-nitrosoglutathione. ${ }^{7}$

It is clear that it is often not NO itself, but rather a number of NO related species that are important for antibacterial effects. Recently, the concept of nitrosative stress has been proposed. ${ }^{89}$ Cellular damage may result from oxidative stress, largely mediated by oxidation of thiol groups, or by nitrosative stress induced by nitrosation of thiol groups and NO related inhibition of enzyme activity. Generation of nitrogen oxides may be involved in both processes with formation of peroxynitrite producing oxidative and nitrosative stress (through generation of $\mathrm{OH}$ and $\mathrm{NO}_{2}$ ) and $\mathrm{NO}$ and nitrosothiols producing predominantly nitrosative stress. 
Why are some bacteria sensitive to one NO related compound and others sensitive to a different NO congener? It seems as though bacteria relatively deficient in low molecular weight thiols (for example, glutathione) are unable to protect themselves against S-nitrosothiols, peroxynitrite and even NO itself; Staphylococci spp fall into this group. Bacteria with high thiol concentrations are resistant to NO itself but are still susceptible to peroxynitrite and S-nitrosothiols; $E$ coli and $S$ typhimurium fall into this group. It is also clear that bacteria may increase their resistance to nitrosative stress and these may be the most virulent of all. Certain transcriptional regulators that determine the expression of antioxidant defence enzymes (for example, superoxide dismutase, glucose-6phosphate dehydrogenase, DNA repair enzymes, catalase, glutathione reductase) are activated in $E$ coli exposed to NO related species. In addition to activation by oxidative stimuli, the transcriptional activator $\operatorname{oxy} R$ is activated by S-nitrosothiols, ${ }^{8}$ and the redox sensitive transcriptional regulator soxRS is activated by authentic NO. ${ }^{9}$ The net effect is to lead to the expression of antioxidant defence mechanisms that render the $E$ coli more resistant to subsequent oxidative and/or nitrosative stress. Are these resistant "superbugs"? Certainly transcriptional activation of soxRS can also lead to antibiotic resistance. ${ }^{9}$

Enzymatic generation of NO by induction of NOS in phagocytic cells is only one form of host defence reliant upon NO. It has been reported in this journal that free NO is generated when the nitrite present in saliva is acidified in the stomach. It is possible that peroxynitrous acid, and nitrosothiols are also formed within the stomach and that together these agents form a first line of defence against ingested microorganisms. In this issue a paper from Benjamin's group (see page 334) demonstrates that Helicobacter pylori is killed by acidified nitrite. The authors speculate that an adequate dietary intake of nitrate may be important to ensure sufficient chemical generation of $\mathrm{NO}$ in the stomach to protect against colonisation of the gastric mucosa by $H$ pylori. The experiments described were done under conditions of relatively low oxygen tension and even then effects were seen only at high concentrations of acidified nitrite $\left(\mathrm{IC}_{50}\right.$ in the order of $\left.200 \mu \mathrm{M}\right)$. From these experiments it is not possible to tell whether the organisms are most sensitive to NO itself or to another NO species. Either way, the organisms seem relatively resistant and it would be important to understand which of the possible mechanisms contribute to resistance: high concentrations of thiols, activation of $\operatorname{oxy} R$ or $\operatorname{soxRS}$, low glutathione transport, expression of NO reductase, etc. It would also be of interest to know whether the organisms are more sensitive to RSNOs or peroxynitrite rather than to authentic NO.

Generation of NO and related compounds within the stomach may be a significant antimicrobial mechanism. Some organisms will not be affected, either because they are innately resistant to nitrosative stress or because they have been primed and have acquired resistance. Some will acquire resistance as a result of exposure to nitrosative stress in the stomach. On the basis of the limited data available $H$ pylori seems to be a relatively resistant strain although this would need to be tested directly in studies in vivo. It would be important to understand the mechanisms of resistance since this might provide a suitable target for drug therapy (for example, an inhibitor of NO reductase). It would also be interesting to determine whether a glass of nitrite or nitrosoglutathine would eradicate the organism. In the enthusiasm to explore these effects it should not be forgotten that $\mathrm{NO}$ and related compounds may damage and be mutagenic to host cells. N-nitroso compounds are carcinogens. Furthermore, $H$ pylori induce expression of NOS in the stomach and it has been suggested that this might underlie the association between chronic infection with $H$ pylori and gastric cancer. ${ }^{10}$

P VALLANCE I CHARLES

Centre for Clinical Pharmacology and Molecular Biology Laboratory,

Wolfson Institute for Biomedical Research,

University College London,

140 Tottenham Court Road,

London W1P 9LN, UK

Moncada S, Higgs EA. Molecular mechanisms and therapeutic strategies related to nitric oxide. FASEB $\mathcal{F}$ 1995;9:1319-30

Fang FC. Mechanisms of nitric oxide-related antimicrobial activity. $\mathcal{F}$ Clin Invest 1997;99:2818-25.

Chen Y, Rosazza JP. Purification and characterization of nitric oxide synthase (NOSNoc) from a Nocardia species. F Bacteriol 1995;177:5122-8. 4 Zumft WG. The biological role of nitric oxide in bacteria. Arch Microbiol 1993;160:253-64.

5 Ji X-b, Hollocher TC. Reduction of nitrite to nitric oxide by enteric bacteria. Biochem Biophys Res Commun 1988;157:106-8.

6 Kono Y, Shibata H, Adachi K, et al. Lactate-dependent killing of Escherichia coli by nitrite plus hydrogen peroxide: a possible role of nitrogen dioxide. coli by nitrite plus hydrogen peroxide:

7 DeGroote MA, Granger D, Xu Y, et al. Genetic and redox determinants of nitric oxide cytotoxicity in Salmonella typhimurium model. Proc Natl Acad nitric oxide cytotoxicity in Salm

8 Hausladen A, Privalle CT, Keng T, et al. Nitrosative stress: activation of the transcription factor OxyR. Cell 1996;86:719-29.

9 Demple B. Redox signalling and gene control in the Escherichia coli soxRS oxidative stress regulon - a review. Gene 1996;179:53-7.

10 Shapiro KB, Hotchkiss JH. Induction of nitric oxide synthesis in murine macrophages by Helicobacter pylori. Cancer Lett 1996;102:49-56.
It is now well established that afferent neurones innervating the intestine subserve "effector" as well as sensory functions. The release of neuromodulators from the peripheral nerve terminals of extrinsic afferents has been shown to play a role in the regulation of blood flow and secretory and motor functions of the gastrointestinal tract. ${ }^{1}$ In animals (but not in humans) most of the extrinsic spinal sensory neurones express calcitonin gene related peptide (CGRP) or substance P, or both. ${ }^{2}$ The role of afferent neu-

\section{Capsaicin sensitivity and epidermal growth factor}

rones and these neuropeptides in the regulation of gastric mucosal integrity has received much attention. Experimental injury in the rat stomach induced by pyloric ligation or injurious factors, such as hydrochloric acid, taurocholate, aspirin, and ethanol, is reduced by stimulation of extrinsic afferent nerve terminals by intragastric administration of capsaicin prior to the injurious agent. In addition, intragastric administration of capsaicin increases gastric mucosal blood flow (GMBF). This protective effect of capsaicin and the increase in GMBF is mimicked by close arterial administration of CGRP and blocked by either functional sensory denervation by neurotoxic doses of capsaicin, or by administration of a CGRP-1 receptor antagonist, $\mathrm{CGRP}_{8-37}$, and by immunoblockade with polyclonal or monoclonal antibodies to CGRP. ${ }^{3}$ 
Epidermal growth factor (EGF) protects against gastric mucosal injury in experimental animals and humans. In the study by Kang et al (see page 344), evidence is provided to support the hypothesis that EGF acts via capsaicin sensitive afferent neurones and release of CGRP, presumably from peripheral nerve terminals. The protective effect of $\mathrm{EGF}$ was abolished by functional sensory denervation. In anaesthetised rats, EGF produced a capsaicin sensitive, CGRP-1 receptor dependent increase in GMBF, an effect which may account for protection against gastric mucosal injury. The authors conclude that EGF increases GMBF by an action on spinal sensory neurones that results in release of CGRP and vasodilatation of arterioles.

These data confirm observations published in abstract form by two other groups, and this interesting study is important for several reasons. It provides solid evidence that an endogenous extragastric agent, EGF, acts via gastric spinal afferent neurones and CGRP to influence gastric mucosal integrity. However, no evidence is presented for a role for endogenous EGF. Thus, in animals with an intact sensory innervation, sialoadenectomy had no effect on the amount of damage caused by ethanol. As the authors point out, the use of absolute ethanol to produce lesions may be too severe a stimulus to show a protective role of endogenous EGF. In this and many other published studies, functional ablation of capsaicin sensitive neurones had no effect on basal GMBF nor on mucosal integrity. In addition, the use of a single dose of EGF does not allow for full comparison or evaluation of the effect of EGF. It must also be considered that mechanisms other than a hyperaemia, such as inhibition of gastric acid secretion, may be responsible for protecting the mucosa. It should be noted that although the data are consistent with a role for CGRP, $\mathrm{CGRP}_{8-37}$ has also been shown to antagonise the effects of amylin (expressed by sensory neurones and gastric endocrine cells) and adrenomedullin (from endothelial cells). ${ }^{45}$ The role of these peptides in afferent nerve mediated gastric hyperaemia or mucosal protection has not been tackled.
What is the pathophysiological significance of these findings? Sensory nerve stimulation has been shown to prevent experimental injury induced by both exogenous and endogenous agents. The protective effect of sensory nerve stimulation by capsaicin and ingestion of chilli is also seen in humans. ${ }^{6}$ Ingestion of chilli powder reduced the aspirin induced damage to the human gastric mucosa assessed by both endoscopy and biopsy. As noted earlier, the human gastric mucosa does not contain neuronal $\mathrm{CGRP}^{7}$ and therefore the neuropeptide that may be responsible for mediating these effects in humans is unknown. It is interesting to speculate on the mechanism by which EGF may stimulate sensory nerve terminals, and whether this is a direct or indirect action. However, until a role for endogenous EGF is established, these remain interesting, but descriptive findings on the multiorgan modulation of function in the gastrointestinal tract.

CURE Digestive Disease Research Centre, UCLA,

H E RAYBOULD

11301 Wiltshire Blvd, Bldg 115,

Los Angeles, CA 90073, USA

1 Holzer P. Local effector functions of capsaicin-sensitive sensory nerve findings: involvement of tachykinins, calcitonin gene-related peptide and other ings: involvement of tachykinins, calcitonin gentes.

2 Green T, Dockray GJ. Characterization of the peptidergic afferent innervation of the stomach in the rat, mouse and guinea pig. Neuroscience 1989;25: 181-93.

3 Holzer P. Peptidergic sensory neurons in the control of vascular functions: mechanisms and significance in the cutaneous and splanchnic vascular beds. Rev Physiol Biochem Pharmacol 1992;121:49-146.

4 Gardiner SM, Compton AM, Kemp PA, et al. Antagonistic effects of human alpha calcitonin gene-related peptide (8-37) on regional hemodynamic actions of rat islet amyloid polypeptide in conscious Long-Evans rats. Diabetes 1991;40:948-51.

5 Entzeroth M, Dodds HN, Wieland HA, et al. Adrenomedullin mediates vasodilation via CGRP-1 receptors. Life Sci 1994;56:19-25.

6 Yeoh KG, Kang JY, Yap I, et al. Chilli protects against aspirin-induced gastroduodenal mucosal injury in humans. Dig Dis Sci 1995;40:580-3.

7 Sundler F, Ekblad E, Hakanson R. Occurrence and distribution of SP- and CGRP-containing nerve fibers in the gastric mucosa. Species differences. In: Costa M, Surrenti C, Gorini S, Maggi CA, Meli A, eds. Sensory nerves In: Costa $\mathrm{M}$, Surrenti $\mathrm{C}$, Gorini S, Maggi CA, Meli A, eds. Sensory nerves
and neuropeptides in gastroenterology: from basic science to clinical perspective. New York: Plenum Press, 1991:29-37.

\section{Feeding the inflamed pancreas}

There is a renewed awareness of the detrimental impact of undernutrition on organ function and clinical outcome. There is also evidence that in some clinical circumstances nutritional support will reverse nutritional depletion and improve recovery. ${ }^{1}$ Nutritional recovery may not be achieved in the metabolically stressed patient. ${ }^{2}$ The effects of nutritional depletion occur early, ${ }^{3}$ and subsequent recovery may be prolonged in the severely depleted patient. ${ }^{4}$ Thus, there is emphasis on early nutritional intervention to prevent or retard the development of malnutrition in patients who are unable to eat or absorb an adequate oral diet. The British Society of Gastroenterology guidelines suggest that such patients should not be deprived of nutrition for more than seven days, and that nutritional support should be considered earlier in patients who are already malnourished or who are metabolically stressed. ${ }^{5}$ The conventional management of patients with acute pancreatitis includes parenteral nutrition, which is instituted early in the course of the illness, partly because of the frequently associated ileus, and partly for fear of the consequences of stimulating pancreatic function by oral nutrition or enteral tube feeding.

Parenteral nutrition is not only expensive, it is potentially hazardous. Problems include complications of catheter placement, catheter associated infection and central vein thrombosis. Although parenteral nutrition will provide most essential nutrients, conditionally essential nutrients such as glutamine are not included in conventional solutions. This may be one reason why parenteral nutrition does not protect gut barrier function, at least in animal experiments. There is an abundance of animal data that luminal nutrition is important for this aspect of intestinal function. ${ }^{67}$ Without luminal nutrition, or possibly in the absence of specific nutrients such as glutamine, there is an increase in intestinal permeability to toxins, and increased translocation of bacteria. ${ }^{7}$ Thus, in the critically ill patient the gut has been considered the motor of multisystem failure with increased permeability and translocation accentuating the cytokine response. Human data are sparse. Some authorities have reported translocation as a spontaneous event which is not increased by bowel rest and conventional parenteral nutrition in the stable patient. ${ }^{8}$ Recent data suggest that enteral nutrition is feasible in patients with pancreatitis. ${ }^{9}$ Thus, a comparison of enteral and parenteral 
feeding in patients with acute pancreatitis is interesting and important.

The study by Windsor and colleagues in this issue (see page 431) compares total parenteral nutrition (TPN) with total enteral nutrition (TEN) in patients with acute pancreatitis. Patients with mild or moderate disease were given oral supplements to tolerance or parenteral nutrition through a peripheral vein. Patients with severe disease received nasojejunal feeding or central parenteral nutrition. The groups were matched for disease severity. Seven days after beginning nutritional support there was an improvement in the APACHE score and $\mathrm{C}$ reactive protein, and reduced length of stay in the ITU in the enterally fed patients in comparison with the patients who received TPN. Furthermore, there was an increase in the anti-endotoxin antibody values and a decrease in the total antioxidant capacity in the TPN group, the antibodies did not change and the antioxidant capacity increased in the TEN group.

The apparent benefit of enteral feeding compared with parenteral feeding is in keeping with current views on the importance of luminal nutrition for the preservation of the intestinal barrier function. However, there are alternative explanations for the differences between the groups in this study. These relate to the amount of nutrition provided and the nature of the energy substrates.

The median number of non-protein calories delivered to the enteral group was 1201 kilocalories per patient day. Oral supplements were given to tolerance and temporary reduction in the volume of feed was required in five of the 16 patients randomised to enteral feeding. By contrast, the parenteral group received all 1800 non-protein calories. We know that the catabolic response to stress cannot be switched off by nutritional support. Cytokines induce proteolysis and lipolysis which provide endogenous substrate for the inflammatory response. Under these circumstances exogenous carbohydrate and lipid may lead to hyperglycaemia and hyperlipidaemia. Thus, nutrition support may be harmful in patients with more severe disease. The possibility that the enteral group fared better because of hypocaloric feeding, or that nutrition support is disadvantageous in this context, cannot be excluded in the absence of a control group maintained on electrolyte infusions for the first week of illness.
Patients who were randomised to receive parenteral nutrition were given $9.4 \mathrm{~g}$ nitrogen, and 1800 non-protein kilocalories, of which 990 calories were supplied as long chain triglycerides. Conversely, the enteral groups were given nutrient solutions in which approximately one third of the energy was supplied as fat. Given the reduced enteral nutrient delivery, this would amount to approximately $40 \%$ of the fat supplied to the parenteral group. The influence of this difference on the modulation of immune function and the generation of proinflammatory cytokines in this context is speculative and uncertain. Nevertheless, long chain triglycerides of the type that are administered during conventional parenteral nutrition have metabolic and immunological effects particularly in the stressed patient. They increase the production of metabolites of arachidonic acid and they may suppress mononuclear phagocyte function. ${ }^{10}$

This is an important clinical study from which we can draw two conclusions. Some of the nutritional needs can be safely provided by the enteral route in patients with acute pancreatitis. Patients who receive enteral feeding fare better than those who are given parenteral nutrition. The reasons for these findings merit further investigation.

C R PENNINGTON

Department of Gastroenterology,

Ninewells Hospital and Medical School,

Dundee DD1 9SY, UK

1 Pennington CR. Disease and malnutrition in British Hospitals. Proc Nutr Soc 1997;56:393-407.

2 Animashaun A, Hill GL. Body composition research: Implications for the practice of clinical nutrition. FPEN 7 Parenter Enteral Nutr 1992;16:197218 .

3 Jeejeebhoy KN. Bulk or bounce - the object of nutritional support. FPEN $\mathcal{F}$ Parenter Enteral Nutr 1988;12:539-45.

4 Keys A, Brozek J, Henschel A. The biology of human starvation. Minneapolis: University of Minnesota Press, 1950

5 British Society of Gastroenterology. Guidelines for nutrition support. London: British Society of Gastroenterology, 1996.

6 Bengmark S. Econutrition and health maintenance - a new concept to prevent GI inflammation, ulceration and sepsis. Clin Nutr 1996;15:110

7 Gardiner KR, Kirk SJ, Rowlands BJ. Novel subtrates to maintain gut integrity. Nutr Res Rev 1995;8:43-66.

8 Sedman PC, Macfie J, Sagar P, et al. The prevalence of gut translocation in humans. Gastroenterology 1994;107:643-9.

9 McCLave SA, Greene LM, Snider HL, et al. Comparison of the safety of early enteral verses parenteral nutrition in mild acute pancreatitis. $\mathscr{P} P N \mathcal{F}$ Parenter Enteral Nutr 1997;21:14-20.

10 Kinsella JE. Lipids, membrane receptors, and enzymes: Effects of dietary fatty acids. FPEN f Parenter Enteral Nutr 1990;14:200S-17S.
In this issue Kouroumalis et al (see page 442) report extended survival in patients with hepatocellular carcinoma (HCC) treated with octreotide, a somatostatin analogue. Somatostatin is a cyclic peptide consisting of 14 amino acids which regulates growth hormone release. It is the product of a multigene family of peptides with two biological derivatives, namely somatostatin 14 and 28. Somatostatin regulates release of growth hormone, thyrotropin and acts as an autocrine and paracrine molecule to suppress neurotransmission, immunocyte activity, smooth muscle contractility, and uptake of nutrients. (reviewed by Lamberts et $a l^{1}$ ). Somatostatin action is mediated through a specific receptor (SSR). Somatostatin suppresses pituitary and adrenal secre-

\section{Octreotide in hepatocellular carcinoma}

tion of growth hormone or thyrotropin after surgery, and inhibits secretory activity of metastatic islet cell tumours such as vipoma, glucagonoma and metastatic carcinoid. It has also been reported to be beneficial in reducing splanchnic circulation and controlling bleeding from oesophageal varices, suppression of fluid secretion by pancreatic and enteric fistula as well as secretory diarrhoea.

Somatostatin receptors were identified recently in a variety of malignant tumours including lung and ovary carcinoma, adenocarcinoma of breast, kidney, colon, and even lymphomas. ${ }^{2-5}$ However, the heterogeneous expression of SSR on the various tumours makes assessment of the antitumour effect(s) of somatostatin difficult. ${ }^{6}$ Octreotide exerts a cell growth regulatory or suppressive effect in various tumours. This effect may operate through inhibition of growth hormone secretion, insulin and gastrointestinal hormones and/or direct effect(s) on production of insulin-like growth factor I or its binding proteins as well as direct inhibition of angiogenesis. On a molecular level, there is evidence that the antimitotic activ- 
ity of somatostatin, mediated through its receptor on the tumour cells, is the result of receptor activation leading to stimulation of tyrosine phosphatase activity. This in turn leads to reversal of epidermal growth factor (EGF) induced phosphorylation of EGF receptor tyrosine kinase. These processes lead, most probably, to shrinkage of individual tumour cells. ${ }^{16}$ Thus, there is a rationale for testing the effect of somatostatin in patients with HCC.

In their article Kouroumalis et al had two goals: (1) semiquantitative determination of somatostatin receptors in liver tissue obtained from patients at various stages of hepatitis and HCC; and (2) assessment of treatment with octreotide ( $250 \mu \mathrm{g}$ twice daily) on survival of patients with HCC with a heterogeneous functional reserve. As to their first goal, the investigators were able to identify somatostatin receptors in liver tissue homogenates obtained from 23 patients in various stages of liver disease, of whom only four had HCC. However, the sample size was small with notable variability of receptor concentration, which does not allow definitive conclusions to be drawn. A more refined method is required to produce membrane preparations from larger tissue specimens which are available at surgery or liver transplantation. Standard reference preparations derived from transformed cell lines ${ }^{78}$ could also be helpful for comparison. As to the second goal, the investigators showed that octreotide treatment had a beneficial effect in a group of 28 patients with HCC in whom median survival was 13 months compared to only four months in 30 control patients who received no treatment. All patients had unresectable HCC and the majority were at Child-Pugh class B-C and Okuda class II or III. Thus, the authors suggest that treatment with octreotide significantly improves survival of patients with HCC and state that the treatment is a valuable alternative for inoperable HCC.

Before embracing this warm recommendation it seems prudent to make a few comments. Physicians who treat patients with HCC are well aware of the many factors that determine the heterogeneous clinical presentation and prognosis of HCC, which include, among others, presence and size of uni- or multifocal tumours, background of cirrhosis, the functional reserve of the liver at time of treatment, the presence or absence of portal hypertension and portal vein thrombosis (reviewed by Bruix ${ }^{9}$ ). The pattern of clinical presentation will dictate the treatment strategy and the chance of survival. It is well agreed that surgical removal/ debulking of unifocal HCC tumours with a diameter $<5 \mathrm{~cm}$ is the initial treatment of choice provided the functional capacity of the liver and the patient's condition permit surgery. However, in most patients and regardless of the aetiological agents involved, surgery is not possible and even in those who undergo successful tumour resection the underlying inflammatory processes will continue to operate as a risk factor for emergence of newly transformed HCC foci. Currently, surgical resection, transarterial chemoembolisation (TAE) and percutaneous ethanol injection (PEI) are the cornerstones of palliative treatment offered to patients with HCC worldwide, ${ }^{9}$ while systemic chemotherapy has been practically abandoned. Clinicians find it difficult to adopt a new form of therapy if data are not derived from adequately controlled studies. HCC has such a variable and heterogeneous course and clinical presentation, that design of well controlled trials for assessment of a new treatment modality is exceedingly difficult. Therefore, the attempt Kouroumalis et al to perform a controlled study at an early stage of assessment of their hypothesis is valuable even in face of some uncertainty as to the validity of matching between groups of patients in their study. It is useful to remind the reader that regardless of the initial treatment modality chosen by individual physicians to treat HCC, most patients will reach a stage where they will need further palliation. In recent years, several non-invasive treatments have been evaluated in these patients, including tamoxifen or retinoic acid derivatives. ${ }^{9}$ Unfortunately, the results of such studies are difficult to analyse as we currently lack the proper methods to make an accurate assessment, prior to initiation of treatment, about adequate recruitment guidelines. The attempt to determine the relative density of somatostatin receptors (SSR) in HCC from biopsy specimens may be of value, although the uniformity of expression of these receptors in HCC tumours remains to be established. Kouroumalis et al have not been able to correlate the density/ concentration of SSR to the success rate of treatment with octreotide. Nevertheless, this study is a beginning. Future studies should tackle the issue of receptor density as measured in purified membrane preparations taken from a larger number of patients and controls. In addition screening for somatostatin receptors with ${ }^{111}$ I-labelled pentertic acid-D-phe-octreotide ${ }^{9}$ may improve selection of candidates for treatment provided that the initial reported efficacy of octreotide in patients with HCC is confirmed.

So far, evaluation of the antitumour effect of somatostatin and its analogues has not been associated with significant adverse effects or even emergence of escape or breakthrough cell growth. Moreover, some patients report an improvement in their well being, an effect which is not necessarily the result of tumour suppression, but could be related to the physiological effects of somatostatin which include reduction of endogenous fluid secretion in the jejunum, stimulation of intestinal fluid and electrolyte absorption, and prolongation of gastrointestinal transit time.

Octreotide treatment is expensive. Based on the protocol suggested by Kouroumalis et al, the estimated annual cost of treatment with $500 \mu \mathrm{g} /$ day could be in the range $£ 6100$ 8000 (US $\$ 10$ 000-13 000). Thus, before adding another new and costly modality to the many (and often experimental) options currently available for treatment of HCC, further studies are required to confirm and extend the preliminary observation. It is tempting to speculate that somatostatin treatment could be used as adjuvant therapy for patients who have already taken advantage of other forms of treatment such as surgical resection, TAE or PEI.

In summary, the promising results of this early study on the effect of octreotide administration on survival of patients with HCC deserve to be explored further. Nevertheless, although the effects of somatostatin analogues on suppression of tumour growth have been documented in some tumours in vitro and in vivo it has yet to be established in patients with HCC that the effects reported by Kouroumalis et al are not indirect effects such as reduced gastrointestinal congestion and pain as well as suppression of growth factors and tumour angiogenesis.

Professor of Medicine,

D SHOUVAL

Director, Liver Unit,

Hadassah University Hospital,

PO Box 12000 ,

Ferusalem 91120, Israel

1 Lamberts SWJ, van der Lely AJ, de Herder WW, et al. Octreotide. N Engl f Med 1996;334:246-54.

2 Weckbecker G, Raulf F, Stolz B, et al. Somatostatin analogues for diagnosis and treatment of cancer. Pharmacol Ther 1993;60:245-64.

3 Reubi JC, Laissue JA. Multiple actions of somatostatin in neoplastic disease. Trends Pharmacol Sci 1995;16:110-15.

4 Robbins RJ. Somatostatin and cancer. Metabolism 1996;45:98S-100S

5 Albers AR, O'Dorisio MS. Clinical use of somatostatin analogues in paediatric oncology. Digestion 1996;57(suppl 1):38-41.

6 Bruns C, Weckbecker G, Ran SG, et al. Molecular pharmacology of somatostatin receptor subtypes. Ann NY Acad Sci 1994;733:138-46.

7 Ren SG, Ezzat S, Melmed S, et al. Somatostatin analog induces insulin like growth factor binding protein-1 (IGFBP-1) expression in human hepatoma cells. Endocrinology 1992;131:2479-81.

8 Warfel KA, Hull MT. Hepatoblastoma: an ultrastructural and immunohistochemical study. Ultrasrtruct Pathol 1992;16:451-61.

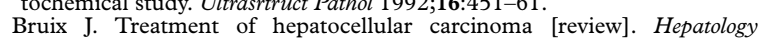
1997;25:259-62. 


\section{Gastro-oesophageal reflux: does it matter what you eat?}

Patients with gastro-oesophageal reflux (GORD) are usually advised to modify their dietary habits. ${ }^{1}$ Among the most popular beliefs is the recommendation to avoid fatty foods which are thought to be detrimental in GORD for several reasons, including reduced lower oesophageal sphincter tone $^{2}$ and delayed gastric emptying. This latter effect may, in turn, result in an increase in the number of transient lower oesophageal sphincter relaxations (TLOSRs) elicited through a vago-vagal reflex originating in the mechanoreceptors located in the subcardial area. ${ }^{3}$ TLOSRs are considered to be the main motor mechanism associated with the occurrence of reflux episodes both in asymptomatic subjects and reflux patients with or without oesophagitis.

With regard to the therapeutic benefit of a low fat regimen in GORD, a review of the literature has shown that there is a paucity of data to support the effectiveness of such a recommendation and no controlled trials. ${ }^{1}$ However, early studies attempted to find a rationale for reduced fat regimens by measuring postprandial oesophageal $\mathrm{pH}$ after a fatty meal in normal subjects and patients with GORD. ${ }^{4}$ As shown in table 1 , the results of studies conducted in normal asymptomatic volunteers were quite conflicting, showing either an increasing effect of fat on upright (but not supine) acid exposure ${ }^{4}$ or exactly the opposite. ${ }^{5}$ However, as far as pathological reflux is concerned, Becker et al had already failed to show the deleterious effect of a high fat meal in patients with GORD, ${ }^{4}$ a result now confirmed by Penagini et al in this issue (see page 330 ). Indeed, after a solid/liquid meal with a high fat content (compared with an equivalent caloric load provided by a balanced meal), these authors observed no significant changes in oesophageal acid exposure during the three hour postprandial period in sitting or recumbent patients, whatever the conditions of $\mathrm{pH}$ monitoring. This study also provides interesting new information regarding the motor mechanisms underlying the pathogenesis of reflux - that is, the basal resting pressure of the lower oesophageal sphincter, the rate of TLOSRs and the number of TLOSRs associated with reflux episodes. Again, no statistical difference was detected relative to the fat content of the meal in both normal controls and patients with reflux (table 2). These results seem at variance with those recently reported in this journal by Holloway et $a l^{6}{ }^{6}$ who showed that intraduodenal infusion of fat increased

Table 1 Influence of the fat content of the meal on postprandial oesophageal acid exposure

\begin{tabular}{|c|c|c|c|}
\hline & Becker et al ${ }^{4}$ & Iwakiri et al ${ }^{5}$ & Penagini et al \\
\hline Subjects & $10 \mathrm{~N}+10 \mathrm{GORD}$ & $20 \mathrm{~N}$ & $13 \mathrm{~N}+14$ GORD \\
\hline \multirow[t]{3}{*}{ Meals } & Solid $(2.47 \mathrm{MJ})$ & Liquid (2.09 MJ) & Solid/liquid (3.18 MJ) \\
\hline & High fat $(61 \%) v$ & High fat $(70 \%) v$ & High fat $(52 \%) v$ \\
\hline & low fat $(16 \%)$ & balanced ( $25 \%$ fat) & balanced ( $24 \%$ fat) \\
\hline \multicolumn{4}{|c|}{ Results } \\
\hline $\begin{array}{l}\text { Normal } \\
\text { subjects }\end{array}$ & $\begin{array}{l}\text { Increased upright } \\
\text { acid exposure }\end{array}$ & $\begin{array}{l}\text { Increased recumbent } \\
\text { acid exposure }\end{array}$ & $\begin{array}{l}\text { NS in both sitting } \\
\text { and recumbent } \\
\text { positions }\end{array}$ \\
\hline GORD & NS & Not tested & $\begin{array}{l}\text { NS in both sitting } \\
\text { and recumbent } \\
\text { positions }\end{array}$ \\
\hline
\end{tabular}

$\mathrm{N}$, asymptomatic healthy subjects; GORD, patients with erosive oesophagitis or abnormal acid exposure, or both, on 24 hour $\mathrm{pH}$ monitoring.
Table 2 Influence of the fat content of the meal on lower oesophageal sphincter motor function and mechanisms underlying episodes of gastro-oesophageal reflux

\begin{tabular}{|c|c|c|}
\hline & Holloway et $a l^{6}$ & Penagini et al \\
\hline Subjects & $12 \mathrm{~N}+11$ GORD & $13 \mathrm{~N}+14$ GORD \\
\hline Meals & $\begin{array}{l}\text { Liquid; intraduodenal } \\
\text { infusion ( } 1 \mathrm{ml} / \mathrm{min} \text { for } 30 \\
\text { min) of fat (Intralipid } 10 \%) \\
v \text { saline }\end{array}$ & $\begin{array}{l}\text { Solid + liquid }(3.18 \mathrm{MJ}) \text {; } \\
\text { Orally + intragastric infusion } \\
\text { of a high fat }(52 \%) v \text { a } \\
\text { balanced }(24 \%) \text { meal }\end{array}$ \\
\hline $\begin{array}{r}\text { Duration of } \\
\text { recording }\end{array}$ & ( & $180 \mathrm{~min}$ \\
\hline Results & & \\
\hline \multicolumn{3}{|c|}{ Basal LOS pressure } \\
\hline $\begin{array}{l}\text { Normal } \\
\text { controls }\end{array}$ & Decreased & NS \\
\hline GORD & NS & NS \\
\hline \multicolumn{3}{|l|}{ TLOSRs } \\
\hline $\begin{array}{l}\text { Normal } \\
\text { controls }\end{array}$ & NS & NS \\
\hline GORD & NS & NS \\
\hline \multicolumn{3}{|c|}{ No of reflux episodes } \\
\hline \multicolumn{3}{|c|}{ Normal } \\
\hline GORD & Increased & NS \\
\hline \multicolumn{3}{|c|}{$\%$ TLOSRs with reflux } \\
\hline $\begin{array}{l}\text { Normal } \\
\text { controls }\end{array}$ & NS & NS \\
\hline GORD & Increased & NS \\
\hline
\end{tabular}

$\mathrm{N}$, asymptomatic healthy subjects; GORD, patients with erosive oesophagitis or abnormal acid exposure, or both, on 24 hour $\mathrm{pH}$ monitoring.

the rate of reflux episodes and the incidence of reflux during TLOSRs, a variable which has been reported to be significantly higher in patients with pathological reflux (GORD) than in normal controls. Methodological differences, especially the short duration of recording and the rather unphysiological meal (100\% fat) tested in the study by Holloway et al (table 2), may easily account for such discrepancies. Moreover, neither study conducted precise investigations of some key parameters-for example gastric tone or the role of cholecystokinin, which is released on contact of the duodenal mucosa with fat and which increases the number of TLOSRs in different species including humans. ${ }^{7-9}$ Finally, regarding the association of TLOSR with reflux, it is noteworthy that other oesophageal motor events could be involved-for example, the, oesophageal body muscular response normally following a TLOSR, ${ }^{10}$ which may be a protective mechanism and which may be impaired in GORD.

Is advice concerning fatty foods still justified in clinical practice? In my opinion, as potent and safe antireflux drugs become increasingly available, there will be less and less room for lifestyle recommendations which may, by themselves, impact the quality of life of patients with reflux without providing any significant benefit. However, clinical experience suggests that fatty foods may be poorly tolerated in some individuals, especially those with dyspeptic symptoms or those with severely delayed gastric emptying, or both, two conditions that are found in a substantial proportion of patients with GORD. In such patients, recommending a low fat diet may be reasonable. In the absence of clear clinical benefit from the patient's point of view, there is no further justification for the doctor to recommend that patients alter their diet.

Department of Gastroenterology and Hepatology,

J P GALMICHE

CHU, Hotel Dieu, 44035 Nantes Cedex, France

1 Kitchin Ll, Castell DO. Rationale and efficacy of conservative therapy for gastroesophageal reflux disease. Arch Intern Med 1991;151:448-54.

2 Nebel OT, Castell DO. Lower esophageal sphincter pressure changes after food ingestion. Gastroenterology 1972;63:778-83.

3 Franzi SJ, Martin CJ, Cox MR, et al. Response of canine lower esophageal

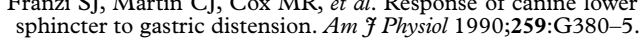


4 Becker DJ, Sinclair J, Castell DO, et al. A comparison of high and low fat meals on postprandial esophageal acid exposure. Am f Gastroenterol 1989;84:782-6. 5 Iwakiri K, Kobayashi M, Kotoyori M, et al. Relationship between postprandial esophageal acid exposure and meal volume and fat content. Dig Dis Sci 1996;41:926-30.

6 Holloway RH, Lyrenas E, Ireland A, et al. Effect of intraduodenal fat on lower oesophageal sphincter function and gastro-oesophageal reflux. Gut 1997;40:449-53.

7 Boulant J, Fioramonti J, Dapoigny M, et al. Cholecystokinin and nitric oxide in transient lower esophageal sphincter relaxation to gastric distention in dogs. Gastroenterology 1994;107:1059-66.
8 Boulant J, Mathieu S, D'Amato M, et al. Cholecystokinin in transient lower oesophageal sphincter relaxation due to gastric distension in humans. Gut 1997;40:575-81.

9 Zerbib F, Bruley Des Varannes S, D'amato M, et al. Effect of the CCK-A receptor antagonist loxiglumide on gastric tone and transient lower esophageal sphincter relaxations in humans [abstract]. Gastroenterology 1997;112:A857.

10 Sifrim D, Janssens J, Vantrappen G. Transient lower esophageal sphincter relaxations and esophageal body muscular contractile response in normal humans. Gastroenterology 1996;110:659-68.

\section{Gut—http://www.gutjnl.com}

Visitors to the world wide web can now access Gut either through the BMJ Publishing Group's home page (http://www.bmjpg.com) or directly by using its individual URL (http://www.gutjnl.com). There they will find the following:

- Current contents list for the journal

- Contents lists of previous issues

- Members of the editorial board

- Subscribers' information

- Instructions for authors

- Details of reprint services.

A hotlink gives access to:

- BMJ Publishing Group home page

- British Medical Association web site

- Online books catalogue

- BMJ Publishing Group books

The web site is at a preliminary stage and there are plans to develop it into a more sophisticated site. Suggestions from visitors about features they would like to see are welcomed. They can be left via the opening page of the BMJ Publishing Group site or, alternatively, via the journal page, through "about this site". 